\title{
Qualidade na educação superior: tendências do século
}

MARILIA COSTA MOROSINI*

\section{RESUMO}

O texto constrói um estado de conhecimento sobre qualidade na educação superior, com base nas perspectivas internacionais que influenciam as nacionais pelo processo de globalização, e identifica as concepçóes de qualidade isomórfica, da especificidade e da equidade e faz uma análise da trajetória do conceito de qualidade universitária e seus organismos propositivos, neste século. Merece destaque a posição da Unesco e de suas ramificaçôes, como a IESALC e a GUNI, na construçáo do conceito de qualidade da educaçáo superior para o desenvolvimento sustentável. São considerados outros contributos advindos de associaçōes de educação superior, como a EAIR, AAIR, OCDE e a AIPU. Constata-se a minimização das diferenças entre os três tipos de qualidade, apesar do predomínio do tipo isomórfico. Registra-se a tendência do uso de índices avaliativos e de medidas de impacto da qualidade universitária, a tendência das pesquisas sobre o estudante e, mais recentemente, sobre o egresso - learning outcomes. A concepção de qualidade não é clara e está relacionada a quem ela é dirigida e por quem ela é definida.

Palavras-chave: ensino superior, qualidade do ensino, avaliação da educação.

\section{RESUMEN}

El texto construye un estado de conocimiento sobre la calidad en la educación superior, basándose en las perspectivas internacionales que influyen en las nacionales debido al proceso de globalización, e identifica las concepciones de calidad isomórfica, de la especificidad, y de la equidad y hace un análisis del recorrido del concepto de calidad universitaria y de sus

* Professora da Faculdade de Educação da Pontifícia Universidade Católica do Rio Grande do Sul (FACED/PUCRS). Coordenadora da Rede UNIVERSITAS/RIES, Núcleo de Excelência em C, T \& I CNPq/FAPERGS, Coordenadora do Observatório de Educação Capes/Inep (morosini@via-rs.net). 
organizaciones proponentes, en este siglo. Merece destacarse la posición de la UNESCO y de sus ramificaciones, como el IESALC y el GUNI, en la construcción del concepto de calidad de la educación superior para el desarrollo sostenible. También se consideran otras contribuciones provenientes de asociaciones de educación superior como la EAIR; AAIR; OCDE y la AIPU. Lo que se constata es la minimización de las diferencias entre los tres tipos de calidad, a pesar del predominio del tipo isomórfico. Se registra la tendencia del uso de índices evaluativos y de medidas de impacto de la calidad universitaria, la tendencia de las investigaciones sobre el estudiante y, más recientemente, sobre el alumno egresado - learning outcomes. La concepción de calidad no es clara y está relacionada con a quién va dirigida y por quién es definida.

Palabras clave: enseñanza superior, calidad de la enseñanza, evaluación de la educación.

\section{ABSTRACT}

This paper develops the state of knowledge of higher education quality from international perspectives that shape the national ones through the process of globalization and identifies the isomorphic, specific, and equity types of quality, and analyzes the roadmap of theses types of quality and their sources. The main source identified is UNESCO and its ramifications, such as IESALC and GUNI. These sources are responsible for the construction of the concept of quality in higher education for sustainable development. Other sources are the so-called higher education associations, such as EAIR, AAIR, AIPU, and OECD. The results of this investigation identified a reduction of the differences between the three types of concept, despite the predominance of isomorphic types. A trend towards the use of evaluation levels in higher education quality and the impact of quality were also identified. It was also identified that the focus of current research is on student and most recently on the alumni community, with the development of the concept of learning outcomes. In addition, the analysis shows that the concept of quality is not clear and is related to whom it is directed and by whom it is determined.

Keywords: higher education, teaching quality, course evaluation. 


\section{INTRODUÇÃO}

Este texto tem como objetivo construir um estado de conhecimento sobre qualidade na educação superior, considerando as perspectivas internacionais que influenciam as nacionais, em razão do processo de globalização. A concepção de qualidade vem imbricada ao desenvolvimento dessas perspectivas, com tempos e espaços próprios. Enquanto na década de $80 / 90$, internacionalmente, discutia-se para além da concepção de qualidade, ou seja, já eram propostas estratégias e medidas para obtê-la, no Brasil, era um tema quase que supérfluo. Com a expansão do Estado Avaliador, a qualidade, como seu substrato, adquire força.

Assim, buscando trazer à tona a relação avaliação-qualidade, escrevi um ensaio no qual registrei que a noção de qualidade na educação apresentava três tipos ideais que poderiam ser encarados como modelos para a realidade brasileira: a qualidade isomórfica, a qualidade da diversidade e a qualidade da equidade (Morosini, 2001).

O presente trabalho retoma o encontrado e faz uma análise da trajetória percorrida quanto ao conceito de qualidade universitária e suas fontes propositivas.

\section{NOÇÕES DE QUALIDADE NA EDUCAÇÃO SUPERIOR}

\subsection{Qualidade isomórfica}

Teorias organizacionais de administração universitária concebem a qualidade como um processo caracterizado por um conjunto de fases: planejamento, ação, avaliação e promoção. No final dos anos 80 e na década de 90 , foi registrado o desvirtuamento da concepçáo de qualidade, como um conjunto de fases, com predominância de uma delas: a da avaliação. São identificadas, no tempo e no espaço, diversas concepçóes e práticas de avaliação: a) desde aquelas dirigidas, prioritariamente, por princípios financeiros até as regidas pela qualidade como substrato educativo; b) desde as baseadas em metodologias que objetivavam simplesmente a avaliação per si até aquelas que visavam a avaliação para credenciamento; c) desde as que avaliavam programas de estudos até as que avaliavam instituiçóes.

Nesta visão a qualidade tende ao conceito de isomorfismo e padronização, e são identificados diversos tipos e padrôes de qualidade (Quadro 1, p. 186) basicamente voltados ao mercado. Nos últimos anos, alguns países da União Europeia (EU), liderados pelo Reino Unido, e também a Austrália vêm desenvolvendo a ideia de que a qualidade do ensino universitário está relacionada com empregabilidade. Knight e Yorke (2003) registram que a empregabilidade é multidimensional e muito complexa de ser avaliada, e constroem um modelo - Understanding, Skills, Employability, Metacognitions (USEM) -, composto de três fatores: qualidades pessoais 
(E), habilidades-chave (S) e o processo de desenvolvimento dessas habilidades (U), metacognição, além da categoria tradicional de conteúdos (Morosini, 2006).

\subsection{Qualidade da especificidade}

É o conceito de qualidade que se encerra nas tendências à diversidade. Traz consigo indicadores de estandardizaçáo, paralelamente à preservação das especificidades. A Unesco considera qualidade e diversidade os eixos das políticas educativas. No documento "Declaração Mundial sobre Educação Superior no Século XXI: visão e ação", resultante da Conferência Mundial sobre Ensino Superior (1998), qualidade em educação superior

é um conceito multidimensional que deve envolver todas as funçóes e atividades: ensino, programas acadêmicos, pesquisa e fomento da ciência, ambiente acadêmico em geral. Uma autoavaliação interna e transparente e uma revisão externa com especialistas independentes, se possível com reconhecimento internacional, sáo vitais para assegurar a qualidade. Devem ser criadas instâncias nacionais independentes e definidas normas comparativas de qualidade, reconhecidas no plano internacional. Visando a levar em conta a diversidade e evitar a uniformidade, deve-se dar atençáo aos contextos institucionais, nacionais e regionais específicos. Os protagonistas devem fazer parte integrante do processo de avaliação institucional. (Delors et al., 2006, p. 47, Art. 11, Alínea a)

A União Europeia tem capitaneado a concepção de busca de qualidade com respeito às especificidades. Tal conduta tem como pano de fundo a concepção do processo de integração entre países: muito mais pelas diferenças do que pelas similaridades. Não à imposição de um padrão único, certo, mas o fortalecimento de princípios e açóes "que deram certo" e a disseminação de tais modelos para vencer os desafios de padróes insuficientes. Entre as inúmeras estratégias a serem desenvolvidas para o fortalecimento das naçóes, são apontados os projetos-piloto, as recomendaçóes sobre qualidade na educaçáo superior e o estabelecimento de uma rede de qualidade - European Quality Assurance Network (ENQA).

\subsection{Qualidade da equidade}

Dois conceitos inseparáveis são defendidos nesta teoria: qualidade e equidade; e a comunidade educativa é responsável pela aplicabilidade e o êxito, ou fracasso, de políticas educacionais de qualidade com equidade. Sáo citados nove fatores-chave para a busca da qualidade com equidade: extensão da educação, tratamento da 
diversidade, autonomia escolar, currículo/autonomia curricular, participação da comunidade educativa e gestão dos centros, direção escolar, professorado, avaliação e inovação e investigação educacionais. É ressaltado que a qualidade está para além da simples padronização de indicadores, abarcando estudos qualitativos e quantitativos (INCE, 1999).

O conceito de qualidade com equidade também é defendido pela Unesco. $\mathrm{Na}$ Reunião do Comitê Regional Intergovernamental do Projeto Principal de Educação na América Latina e Caribe (PROMEDLAC VII), os ministros da educação concluíram com a adoção da Declaração de Cochabamba, dando seguimento ao Foro Mundial sobre a Educação, realizado em Dakar, em abril de 2000.

Parte-se da aceitação que o uso pedagógico das tecnologias de informação e comunicaçáo deve ocorrer no marco de um projeto social e educativo comprometido com a equidade e com a qualidade. ... não podemos esquecer que a opção de tornar mais eficientes essas aprendizagens deve considerar mais as potencialidades das pessoas - e muito particularmente dos professores - e o respeito às identidades culturais, antes que as próprias promessas da tecnologia. (Unescopresse, 2000, p.4)

Mais recentemente, em 2008, a Organização para a Cooperação e Desenvolvimento Econômico (OCDE) edita uma série de publicaçóes sobre educação superior, e uma delas é destinada à equidade:

Equity in education has two dimensions. The first is fairness, which implies ensuring that personal and social circumstances - for example gender, socioeconomic status or ethnic origin - should not be an obstacle to achieving educational potential. The second is inclusion, which implies ensuring a basic minimum standard of education for all - for example that everyone should be able to read, write and do simple arithmetic. The two dimensions are closely intertwined: tackling school failure helps to overcome the effects of social deprivation, which often causes school failure'. (Santiago et al., 2008, p. 73)

\footnotetext{
${ }^{1}$ Equidade em educação tem duas dimensões. A primeira é a justiça, a qual pressupooe que circunstâncias pessoais e sociais - por exemplo, sexo, status socioeconômico ou origem étnica - não devem ser um obstáculo ao desenvolvimento do potencial educativo. A segunda é a inclusão, a qual implica assegurar um padrão básico mínimo de educação para todos - por exemplo, que todos devem ser capazes de ler, escrever, e fazer cálculos aritméticos simples. As duas dimensóes estão intimamente ligadas: combater o insucesso escolar ajuda a superar os efeitos das carências sociais, as quais, muitas vezes, são responsáveis por esse fracasso.
} 
A OCDE detalha mais um pouco as características dos indivíduos que perseguem a equidade na educaçáo superior:

Those that ensure that access to participation in and outcomes of tertiary education are based only on individuals' innate ability and study effort. They ensure that educational potential at tertiary level is not the result of personal and social circumstances, including of factors such as socioeconomic status, gender, ethnic origin, immigrant status, place of residence, age, or disability ${ }^{2}$. (Santiago et al., 2008, p. 74)

O sistema educacional será equitativo quando os resultados da educação e da formação do alunado não dependerem de fatores geradores de "características iniciais", e quando o tratamento em relaçáo à aprendizagem corresponder às necessidades específicas de cada um (Felicetti; Morosini, 2009).

\section{PERSPECTIVAS DA QUALIDADE NA EDUCAÇÃO SUPERIOR}

O jogo de tensões e de incertezas na educação superior, que vem acompanhando o desenrolar deste século, está sendo marcado pela tendência à concepção de qualidade como compromisso com o desenvolvimento humano e social. Não somente determinada por organismos multilaterais, mas uma concepção que considere o sul (países em desenvolvimento) e as diferenças entre os países do norte (caso da UE), e a busca de equidade.

No patamar de hoje o ensaio escrito em 2001, e anteriormente resumido, se mantém. As três perspectivas estão presentes na realidade mundial: a qualidade isomórfica, a qualidade da diversidade e a qualidade da equidade. O que pode ser considerado diferente é não mais a separação nítida entre as três categorias de qualidade: as fronteiras estão mais atenuadas. Também é de registrar que ainda é marcante a qualidade isomórfica. A ideia da qualidade como equidade vem se construindo. Poderíamos ainda dizer que as fronteiras entre a tipologia identificada estáo se atenuando principalmente entre a noçáo de qualidade para a diversidade e qualidade para a equidade. E a Unesco se destaca nessa consolidação.

\footnotetext{
${ }^{2}$ Sistemas terciários equitativos são aqueles que asseguram que o acesso, a participação e o resultado do ensino superior são baseados somente na habilidade inata do indivíduo e no esforço do estudo. Eles garantem que o potencial educativo, em nível superior, não é resultado de circunstâncias pessoais e sociais, incluindo fatores como situação socioeconômica, sexo, origem étnica, status de imigrante, local de residência, idade ou deficiência.
} 


\subsection{A Unesco e a qualidade para o desenvolvimento sustentável}

A Unesco determina como meta das Naçôes Unidas, no decênio 2005-2014, a Educación para el Desarrollo Sostenibel, para promover e melhorar a educaçáo básica; reorientar os programas de educaçáo para o desenvolvimento sustentável; desenvolver a consciência e a compreensão pública sobre a sustentabilidade; aprimorar a formação e incluir a educação superior.

Para consolidar essa posiçáo, em outubro de 2007, na reuniáo dos ministros da educação dos 96 países que compóem a Unesco, foi elaborado um "comunicado" que versa sobre "direitos à educação e desenvolvimento; contribuiçóes da educação ao crescimento econômico; educação e desenvolvimento sustentável; alianças para a educação e desenvolvimento econômico". Nesse comunicado, é solicitado que a Unesco

- preste mayor atención a la cooperación entre múltiples partes interesadas en la educación y vele para que los vínculos con el desarrollo económico sostenible constituyan un tema permanente en sus programas y actividades;

- inicie un proceso de reflexión sobre las funciones respectivas del Estado y otras partes interesadas en la reglamentación, la organización y el suministro de la educación en contextos en que el sector privado contribuye cada vez más a ampliar el acceso y a mejorar la calidad de la enseñanza;

- preste particular atención a las necesidades de los Países Menos Adelantados (PMA) y las necesidades de los Pequeños Estados Insulares en Desarrollo;

- fortalezca su función de coordinación en el Decenio de las Naciones Unidas de la Educación para el Desarrollo Sostenible (DEDS) ${ }^{3}$, la Educación para Todos ${ }^{4}$ y el Decenio de las Naciones Unidas de la Alfabetización a fin de que la combinación de la educación y el desarrollo económico brinde una esperan-

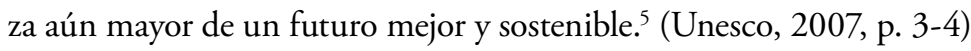

${ }^{3}$ São considerados temas chaves: igualdade de gênero, promoção da saúde, meio ambiente, desenvolvimento rural, diversidade cultural, paz e segurança humana, urbanização sustentável e consumo moderado.

${ }^{4}$ Até 2015 , deverão estar suplantadas as necessidades de aprendizagem de todas as crianças, jovens e adultos.

5 • dê maior atenção à cooperação entre os diversos segmentos interessados na educação e zele para que a relação com o desenvolvimento econômico sustentável seja tema permanente em seus programas e atividades;

- inicie um processo de reflexão sobre as funçóes respectivas do Estado e de outros segmentos interessados na regulamentaçáo, na organizaçáo e na submissão da educaçáo em contextos em que o setor privado contribua, cada vez mais, para ampliar o acesso ao ensino e a melhorar sua qualidade; 
Para a Unesco, a educação é o principal agente da transição para o desenvolvimento sustentável, incrementando a capacidade de as pessoas tornarem realidade suas concepçóes de sociedade. A educação não se limita a desenvolver capacidades científicas e técnicas; também fortalece a motivação das pessoas, a justificação e o apoio social àquelas que os buscam e os aplicam. A educação para o desenvolvimento sustentável se percebe como um processo de aprendizagem para tomar decisóes que tenham em conta, em longo prazo, o futuro da economia, a ecologia e a equidade de todas as comunidades. Criar condiçóes para delinear cenários futuros constitui-se na principal missão da educação.

Para a Unesco, é impossível ter uma educação voltada para o desenvolvimento sustentável, se ela não tiver qualidade. Mas o que é educação de qualidade?

La calidad se ha convertido en un concepto dinámico que tiene que adaptarse permanentemente a un mundo cuyas sociedades experimentan hondas transformaciones sociales y económicas. Es cada vez más importante estimular la capacidad de previsión y anticipación. Ya no basta con los antiguos criterios de calidad. A pesar de las diferencias de contexto, existen muchos elementos comunes en la búsqueda de una educación de calidad que debería habilitar a todos, mujeres y hombres, para participar plenamente en la vida comunitaria y para ser también ciudadanos del mundo. ${ }^{6}$ (Unesco, 2001, p.1)

A educação de qualidade tem como características essenciais: apoio ao enfoque fundamentado nos direitos de todos a todos os esforços educativos para seu desenvolvimento pleno. A Educação é um direito humano; consequentemente, a educaçáo de qualidade apoia todos os direitos humanos; tem fundamento nos quatro

- dê especial atenção às necessidades dos países menos desenvolvidos e às carências dos pequenos estados insulares em desenvolvimento;

- fortaleça seu papel de coordenação no Decênio das Naçôes Unidas da Educação para o Desenvolvimento Sustentável (DEDS), a Educação para Todos e o Decênio das Nações Unidas da Alfabetização, a fim de que a combinação de educação e desenvolvimento econômico ofereça a esperança ainda maior de um futuro melhor e sustentável.

${ }^{6}$ A qualidade se transformou em um conceito dinâmico que deve se adaptar permanentemente a um mundo que experimenta profundas transformaçôes sociais e econômicas. É cada vez mais importante estimular a capacidade de previsão e de antecipação. Os antigos critérios de qualidade já não são suficientes. Apesar das diferenças de contexto, existem muitos elementos comuns na busca de uma educação de qualidade que deveria capacitar a todos, mulheres e homens, para participarem plenamente da vida comunitária e para serem também cidadãos do mundo. 
pilares da educação para todos - aprender a conhecer, aprender a fazer, aprender a conviver e aprender a ser (Delors et al., 2006) e considera o estudante um indivíduo, membro de uma família, de uma comunidade e cidadáo do mundo, que aprende para se tornar competente em seus quatro papeis; defende e propaga os ideais de um mundo sustentável - um mundo justo, equitativo e pacífico no qual as pessoas se preocupam com o meio ambiente para contribuir a equidade intergeracional; leva em consideração o contexto social, econômico e o meio ambiente e configura o currículo como o programa para refletir essas condições específicas. A educação de qualidade é localmente importante e culturalmente adequada; está conformada pelo passado (por exemplo, conhecimentos autóctones e tradicionais), é significativa no presente e prepara as pessoas para o futuro; constrói conhecimentos, habilidades vitais, perspectivas, atitudes e valores; oferece instrumentos para tornar mais sustentáveis as sociedades atuais; e é possível mensurá-la.

O movimento liderado pela Unesco tem reflexos na IESALC/Unesco - ramificação da organização para a América Latina. Discutem-se ${ }^{7}$ concepçôes e princípios e define-se como "compromisso social das universidades da América Latina e Caribe" a aplicação de políticas institucionais que adotem o princípio da educação como bem público, em consonância com os valores de qualidade, pertinência, inserção e equidade (Encontro..., 2007).

Além das conferências voltadas à concepção de universidade comprometida com o desenvolvimento social, a IESALC vem promovendo projetos interculturais que apoiam essa concepção.

Suele reservarse el uso de la idea de "interculturalidad" para calificar exclusivamente a programas y experiencias que procuran reconocimiento y respeto mutuo entre grupos humanos culturalmente diversos. Sin embargo, un uso más cuidadoso del término "interculturalidad" obliga a incluir bajo este concepto todo tipo de experiencias humanas caracterizadas por la importancia de dinámicas de relación entre grupos humanos que se perciben mutuamente como culturalmente diversos, sea que éstas puedan calificarse como positivas o negativas. El

${ }^{7} 1^{\circ}$ Congresso Latino-americano de Reitores e Redes Universitárias (novembrode 2006, Brasília); $2^{\circ}$ Congresso Latino-americano de Reitores eRedes Universitárias (maio de 2007, Caracas); SeminárioInternacional Transformaciones Socialesy Desafíos UniversitariosenAmérica LatinayelCaribe, (12 y 13 de Julio, 2007, Buenos Aires); Encontro Internacional de Reitores relacionado ao tema do compromisso social (outubro de 2007, UFMG/Brasil); Conferência Regional de Educação Superior (Cartagena, 2008) e Conferência Mundial de Educação Superior (CMES) (Paris, 2009). Disponível em: <www.iesalc/unesco $>$. 
proyecto está orientado a analizar no sólo las cada vez más numerosas y diversas experiencias de universidades interculturales, indígenas y afrodescendientes, que se están desarrollando en la región, sino también otros tipos de experiencias de carácter intercultural actualmente en marcha en el ámbito de la educación superior. $^{8}$ (Encontro..., 2007, p.1)

Outras associaçóes ligadas à Unesco também buscam consolidar e discutir essa concepção de qualidade. A Global University Network for Innovation (GUNI) aborda esse tema, tanto em sua revista como em eventos.

No primeiro caso, em seu número de 14 de novembro de 2007, o artigo "La universidade socialmente responsable: una manera de ser" destaca o projeto "Universidad Construye Pais", que pretende realizar uma ação coordenada e conjunta de responsabilidade social em universidades chilenas. Esse projeto foi criado em 2001 e acredita na responsabilidade social como a ética que impulsiona a ação.

Considera Responsabilidade Social Universitária (RSU) a capacidade que a universidade, como instituição, tem de difundir e colocar em prática um conjunto de princípios e valores, por meio de quatro processos chaves: gestáo, docência, investigação e extensão. Os valores e princípios declarados são: no plano pessoal - dignidade da pessoa, liberdade, integridade; no plano social - bem comum e equidade social; desenvolvimento sustentável e meio ambiente; sociabilidade e solidariedade para a convivência; aceitação e apreço a diversidade; cidadania, democracia e participação; e no plano universitário - compromisso com a verdade; excelência; interdependência e transdisciplinaridade (La Jara, 2007).

Nessa mesma linha de pensamento o boletim da GUNI define a RSU como: uma política de qualidade ética do desempenho da comunidade universitária (estudantes, docentes e pessoal administrativo) por meio da gestão responsável dos im-

${ }^{8}$ A ideia de "interculturalidade" é utilizada para qualificar exclusivamente a programas e experiências que procuram reconhecimento e respeito mútuo entre grupos humanos culturalmente diversos. Entretanto, o uso mais cuidadoso do termo "interculturalidade" obriga a incluir nesse conceito todo tipo de experiências humanas caracterizadas pela importância de dinâmicas de relação entre grupos humanos que se percebem mutuamente como culturalmente diversos, seja que estas podem se qualificar como positivas ou negativas. $O$ projeto tem por objetivo analisar não somente as cada vez mais numerosas e diversas experiências de universidades interculturais, indígenas e afrodescendentes, que estão se desenvolvendo na região, mas também outros tipos de experiências de caráter intercultural atualmente em curso no âmbito da educação superior. 
pactos educacionais, cognitivos, trabalhistas e ambientais. Tais impactos são gerados pela universidade, em um diálogo participativo, com a sociedade para promover o desenvolvimento humano sustentável (Vallaeys, 2007).

As áreas de impacto da universidade com responsabilidade sustentável são:

Impacto Organizacional. Equivalente a la Responsabilidad Social Empresarial. Toda organización, por ser tal, produce impactos por medio de su gestión. Debería existir una ética de la Gestión, donde los valores estuvieran en el centro y donde esta ética se expresara en el clima laboral; en la relación con los clientes y proveedores; en la relación con los funcionarios - académicos y administrativos - y en la relación con sus estudiantes. En esta área de impactos hay que desarrollar un conjunto de políticas de responsabilidad social, relacionadas a cada uno de los aspectos antes señalados.

Impacto Ambiental. Las universidades producen impactos en el medio ambiente, tales como desechos o residuos contaminantes; uso indiscriminado de agua y energía; ruidos molestos; basuras sin separación en el origen. A su vez la universidad puede concienciar a su alumnado sobre los problemas ambientales a los que se enfrenta la sociedad y contribuir activamente a superarlos.

Impacto Educativo. Cuando los alumnos se forman como ciudadanos democráticos; cuando la comunidad universitaria tiene la posibilidad de participar activamente en proyectos de servicio a la comunidad; cuando participan en la reflexión de las experiencias realizadas; cuando los miembros de la comunidad educativa se comprometen voluntariamente en proyectos de servicio; cuando hay un trabajo interdisciplinario en proyectos de servicio a la comunidad; cuando se producen mejoras continuas en los currículo a partir de las experiencias realizadas, etc.

Impacto Cognitivo. Cuando las líneas de investigación se abren a temas del desarrollo humano sostenible; cuando los proyectos de investigación asumen los temas étnicos; de género; de pobreza; de la discapacidad; cuando los proyectos de investigación incluyen la integración de diversas perspectivas disciplinarias; cuando hay un aprendizaje compartido con otros actores de la comunidad; cuando el conocimiento generado cumple con los estándares establecidos por la universidad sobre calidad y pertinencia; cuando los conocimientos generados son difundidos entre la comunidad académica, entre los actores relevantes en el tema y en la opinión pública en general, etc.

Impacto Social. Cuando la universidad abre sus puertas y recibe alumnos de los sectores más desfavorecidos de la población; cuando la universidad se hace cargo 
de sus alumnos reales y logra que se mantengan en el sistema con buenos rendimientos; cuando desarrolla programas para nivelar a los estudiantes en competencias básicas; cuando trabaja la deserción y la titulación oportuna; cuando cuenta con una serie de beneficios estudiantiles que permiten realizar lo descrito; cuando los proyectos sociales que emprende la universidad han cumplido con los objetivos que se plantearon; cuando la universidad mantiene convenios con actores sociales para desarrollar proyectos conjuntos; cuando las acciones emprendidas tienen un alcance significativo; cuando hay un presupuesto de la universidad destinado al vínculo con los actores sociales relevantes de la comunidad, etc.' (Zaffaroni, 2007, p. 1)

\footnotetext{
${ }^{9}$ Impacto Organizacional. Equivale à Responsabilidade Social Empresarial. Toda organização, por sua natureza, produz impactos por meio de sua gestão. Deveria existir a ética da gestão, na qual os valores estivessem no centro, e essa ética se manifestaria no clima do trabalho; na relação com os clientes e fornecedores; na relação com os funcionários - acadêmicos e administrativos - e na relação com os estudantes. Nessa área de impactos, deve-se desenvolver um conjunto de políticas de responsabilidade social, relacionadas a cada um dos aspectos assinalados.
}

Impacto Ambiental. As universidades produzem impactos no meio ambiente, como: dejetos e resíduos que contaminam; uso indiscriminado de água e energia; ruídos que incomodam; lixo não reciclado. Por sua vez, a universidade pode conscientizar seu alunado sobre os problemas ambientais que a sociedade enfrenta e contribuir ativamente para superá-los.

Impacto Educativo. Quando os alunos se formam como cidadãos democráticos; quando a comunidade universitária tem a possibilidade de participar ativamente em projetos de serviço para a comunidade; quando refletem sobre as experiências realizadas; quando os membros da comunidade educacional se comprometem voluntariamente em projetos de serviço; quando há um trabalho interdisciplinar em projetos de serviço para a comunidade; quando se realizam melhorias contínuas nos currículos com base nas experiências realizadas, etc.

Impacto Cognitivo. Quando as linhas de investigação tratam de temas relacionados ao desenvolvimento humano sustentável; quando os projetos de pesquisa desenvolvem temas étnicos; de gênero; de pobreza; de discapacidade; quando os projetos de investigação incluem a integração de diversas perspectivas disciplinares; quando há uma aprendizagem compartilhada com outros membros da comunidade; quando o conhecimento gerado cumpre com os padróes estabelecidos pela universidade sobre qualidade e pertinência; quando os conhecimentos gerados são difundidos na comunidade acadêmica, entre os atores relevantes do tema e na opiniáo pública em geral, etc.

Impacto Social. Quando a universidade abre suas portas e recebe alunos das camadas mais desfavorecidas da população; quando a universidade se responsabiliza por seus alunos e consegue que permaneçam no sistema com bons rendimentos; quando desenvolve programas para nivelar os estudantes em competências básicas; quando trabalha a evasão e a titulação oportuna; quando conta com uma série de benefícios estudantis que permitem realizar o descrito; quando os projetos sociais que a universidade empreende cumpriram os objetivos a que se propuseram; quando a universidade mantém convênios com atores sociais para desenvolver projetos conjuntos; quando 
No Espaço Europeu de Educação Superior (EEES), proposto pela EU, a ajuda da universidade ao social pressupóe que contribua com o seu território fundamentalmente em duas coisas. Primeiro, na "geração de riqueza mediante programas de formação adaptados ao entorno", formação de líderes sociais, transferência de resultados da universidade à sociedade e ao setor produtivo. Segundo, que a universidade seja "a voz da sociedade ante os problemas sociais", que reivindique os valores europeus de democracia, o humanismo, a racionalidade, a laicidade, e o status do cidadão.

Além de disseminar a ideia de desenvolvimento sustentável, por meio da universidade, a GUNI promoveu, em abril de 2008, a IV Conferência Internacional de Educação Superior no mundo: novas direçôes e papeis emergentes para o desenvolvimento humano e social ${ }^{10}$.

O desenvolvimento humano significa muito mais que o aumento ou a queda da renda nacional, significa criar meios para que as pessoas possam desenvolver todo o seu potencial. Ética e pertinência do conhecimento científico: que conhecimento para que sociedade? Tecnologias do conhecimento para a transformação social; Educação superior e equidade de gênero; $O$ papel da educação superior na construção da paz e dos processos de reconciliação; Educaçáo superior para o diálogo intercultural e o muticultural; Papeis responsabilidades e necessidades da educação superior para o desenvolvimento sustentável; Educação superior e cidadania, participação e democracia. (Conferência..., 2008, p. 4)

\subsection{Qualidade, acreditaçáo, atores, questionamentos}

O tema da qualidade da educação é também objeto de outras associações voltadas à educação superior. A Association Internationale de Pédagogie Universitaire $(A I P U)$ é composta por um grupo de profissionais, de formadores e de experts, e

as açôes empreendidas têm um alcance significativo; quando há um orçamento da universidade destinado ao vínculo com os atores sociais relevantes para a comunidade, etc.

${ }^{10}$ Temas abordados: preparar as novas geraçóes: finalidade educativa e planos de estudos da educação superior para o desenvolvimento humano e social; renovar a criação do conhecimento. $\mathrm{O}$ papel da pesquisa na educação superior: implicações e tendências para uma contribuição ativa futura para o desenvolvimento humano e social; melhorar o diálogo entre a universidade e a sociedade: como a educaçáo superior contribui para o desenvolvimento humano e social por meio do compromisso civil; transformar as instituiçóes de educação superior, a fim de aproveitar as oportunidades criadas pela globalização: principais tendências e respostas institucionais. Perspectivas regionais sobre o papel das instituiçóes de educação superior para o desenvolvimento humano e social: principais tendências na África Subsahariana, Estados Árabes, Ásia e Pacífico, Europa, Estados Unidos e Canadá, América Latina e Caribe. 
escolheu como tema de seu encontro anual de 2008: "O desafio da qualidade no ensino superior: em direção a mudança de paradigma”.

O editorial do congresso afirma que a qualidade na educação superior é hoje o centro das preocupaçóes dos Estados e dos estabelecimentos que emitem títulos e diplomas, pois querem que seus estudantes se tornem competitivos e se insiram no mercado de trabalho, bem como respondam às necessidades do desenvolvimento humano, social, econômico e cultural do país. Essa posição é mundial e se traduz na publicação de textos, regras e orientaçóes.

La qualité dans l'enseignement supérieur au niveau mondial entre donc désormais dans des politiques institutionnelles destinées à valider la qualité des diplômes et de prestations qui y conduisent. Son management concerne l'ensemble des parties prenantes, gouvernements, organismes de reconnaissance académique, établissements prestataires, personnels enseignants et administratifs, étudiants, partenaires professionnels, organismes certificateurs... ${ }^{11}$

L’adhésion des acteurs de l'enseignement supérieur dans le domaine de la qualité se heurte encore à de nombreux obstacles culturels, matériels, d'ordre sémantique. Culture de la qualité? Management de la qualité? Démarche qualité? Assurance qualité ? Autant d'approches aux finalités voisines qui, au travers de l'évaluation, ciblent l'amélioration, la performance, l'excellence mais par des voies qui divisent encore la communauté universitaire... Pour universaliser cette entrée dans la qualité, l'adhésion de tous les acteurs s'impose en particulier celle des personnels enseignants. ${ }^{12}$ (AIPU, 2008)

A European Association on Institutional Research (EAIR), com mais de 30 anos de existência, reunindo pesquisadores e gestores da educação superior, basicamente

${ }^{11}$ A qualidade do ensino superior em âmbito mundial se insere, de agora em diante, no contexto das políticas institucionais destinadas a validar a qualidade dos diplomas e dos serviços que orientaram sua obtenção. A gestão envolve todas as partes interessadas: governo, entidades de reconhecimento acadêmico, estabelecimentos de prestação de serviços, pessoal de ensino e administrativo, estudantes, parceiros profissionais, entidades de certificação...

${ }^{12}$ A adesão dos atores do ensino superior ao campo da qualidade enfrenta ainda numerosos obstáculos de ordem cultural, material e semântico. Cultura da qualidade? Gestão da qualidade? Diligências sobre a qualidade? Certeza de qualidade? Muitos são os enfoques com finalidades semelhantes que visam, por meio da avaliação, melhorar a performance, a excelência, mas cuja voz ainda divide a comunidade universitária... Para universalizar a entrada na qualidade, impóe-se a adesão de todos os atores, especialmente dos professores. 
dos estados do norte da Europa, vem se questionando sobre a certeza das açóes e estratégias implantadas para o desenvolvimento da educação superior. Em 2006, as questôes centrais se referiam à qualidade: o que é cultura da qualidade? Podem, as políticas de qualidade mudar o seu rumo? Pode a qualidade objetivamente ser mensurada, e se for o caso isso deve ocorrer? A avaliação externa de qualidade melhora a qualidade da educação superior?

Em 2008, o tema de seu encontro anual se mantém nessa mesma linha Polishing the silver: are we really improving higher education? A centralidade das preocupaçóes com a qualidade universitária questiona se os procedimentos de busca de qualidade acarretam uma mudança real ou é meramente a retórica da educação superior atual.

Does the shift in language from improvement to enhancement indicate a shift towards shining up appearances rather than a fundamental improvement or is enhancement meant to give the concept of improvement a new dimension? Do quality assurance and evaluation really lead to improvement and if so, of what? "Improvement" arguably has negative connotations: something must be wrong if it needs improving. Have we thus moved away from the notion of continual improvement? What evidence do we have that quality systems have led to improvement? What do we mean by improvement and in what has it occurred? Have we improved the student experience or has the student experience declined? What would be the criteria for making such a judgment? ${ }^{13}$ (EAIR, 2008, p.1)

Entre as tendências de qualidade que vêm se consolidando no panorama mundial, é forte a busca de uma comparação universal ou pelo menos regional da educação superior.

Em setembro de 2008, a OCDE realizou o Seminário Internacional Outcomes of higher education: quality, relevance and impact/Enseignement supérieur: qualité, per-

${ }^{13}$ Será que a mudança do termo "melhoria" para "aperfeiçoamento" indica uma troca para valorizar as aparências, em vez de uma melhoria fundamental, ou aperfeiçoamento pretende dar ao conceito de melhoria uma nova dimensão? A garantia de qualidade e a avaliação realmente conduzem a uma melhoria e, em caso afirmativo, de quê? "Melhoria", indiscutivelmente, tem conotaçóes negativas: algo deve estar errado, se precisa melhorar. Afastamo-nos, então, da idéia de melhoria contínua? Que evidências temos de que os sistemas de qualidade levaram à melhoria? O que entendemos por melhoria e de que maneira ela ocorreu. Nós melhoramos a prática do estudante ou ela piorou? Quais são os critérios para realizar esse julgamento? 
tinence et impact (Educação superior e resultados: qualidade, relevância e impacto). Um dos palestrantes principais foi o presidente da Associação das Universidades de Pesquisa da Alemanha, que se expressou quanto ao título do Seminário:

These criteria, by the way are not new, nor is society's interest in them. The innovation is in the process and the scope of the measuring. And it is there that we are struggling to find a balance between international transparency and comparability on the one hand and academic professional quality culture and individual performance on the other. ${ }^{14}$ (Noorda, S., 2008)

Como uma das conclusôes, resta o desafio ao processo de avaliação da qualidade de considerar, na análise, os inputs, os processos e produtos e náo somente os resultados. A tendência mundial é adotar o modelo learning outcomes - o que a pessoa com qualificação específica é capaz de conhecer, compreender e desempenhar. A qualificaçáo é considerada a ponte entre o desenvolvimento do conhecimento pela educação e as demandas advindas do mundo do trabalho. É medida comparandose o que os estudantes aprenderam e o que esperavam aprender durante o curso. Em pesquisa na União Europeia as competências mais destacadas da carreira são: Domínio da área ou disciplina; Capacidade para trabalhar em equipe; Capacidade para adquirir com rapidez novos conhecimentos e pensamento analítico; Capacidade para render sobre pressão; Capacidade para redigir informes ou documentos; Capacidade para usar o tempo de forma efetiva; Capacidade para coordenar atividades; Capacidade para fazer-se entender; Capacidade para apresentar em público produtos, ideias ou informes ${ }^{15}$ (CEGES, 2008).

${ }^{14}$ Esses critérios não são novos, nem o interesse da sociedade pelos mesmos. A inovação está centrada no processo e na amplitude das medidas. É claro que estamos nos esforçando para encontrar o equilíbrio entre transparência internacional e comparabilidade, por um lado, e cultura da qualidade acadêmica profissional e desempenho individual, por outro.

${ }^{15}$ Dados do projeto REFLEX (Research into Employment and Professional Flexibility) - Pesquisa sobre a flexibilidade de trabalho e profissional, que tem como foco o estudo do profesional flexible, por meio das seguintes questôes: 1) que competências os graduados universitários têm que adquirir para atuar de modo adequado na sociedade do conhecimento? 2) que papel têm os centros de educação superior para ajudar os graduados universitários a desenvolver essas competências? Esse projeto é oriundo do projeto CHEERS (Schomburg, Teichler, 2008), desenvolvido em 1998 e início de 1999 com 3.000 graduados universitários em nove países da União Europeia (Áustria, Finlândia, França, Alemanha, Itália, Países Baixos, Espanha, Suécia e Reino Unido), um país da EFTA (Noruega), um dos países da Europa Central e do Leste em transição (República Checa) e um país economicamente desenvolvido fora da Europa (Japão) 
Entretanto, fica clara a complexidade e ambiguidade dos conceitos e a inexistência de uma concepção precisa para learning outcomes. De modo amplo, é traduzida como resultados. Mas náo há grande preocupação com a precisão conceitual, pois a preocupação está centrada na implantação desse conceito.

Marginson (2009), autor americano, nessa linha de pensamento afirma que se faz necessário compreender o seu modus operandi, o qual requer a incorporaçáo da dimensão cultural e social. $\mathrm{O}$ autor se baseia no termo global knowledge economy ou k-economy (economia do conhecimento). Buscando entender o papel do conhecimento no crescimento da economia, tal lógica implica a dinâmica de abertura das fontes de conhecimento, fato sem precedente na história humana. A dinâmica é baseada na hiperabundância e não na escassez, ou seja, muito diferente da produção industrial convencional. Os bens do conhecimento multiplicam-se à medida em que são disseminados. Nessa economia, a produção e a disseminação dos bens do conhecimento, a criação de redes de comunicação ativas e a emergência do mercado são processos convergentes.

Nesse contexto da k-economy, metodologicamente, há a predominância de rankings universitários mundiais que se constituem em um sistema com credibilidade para comparar o desempenho de pesquisas e o desempenho institucional no ensino e na pesquisa e/ou na empregabilidade. Os rankings são classificaçóes de IES já utilizadas em países como Estados Unidos, China, e em discussão na Europa. Os principais rankings são: Shanghai Jiao Tong University; Times Higher Education (4 anos de existência); Webometrics (2008) (presença na internet); National Survey of Student Engagement (NSSE), 2000; Carnegie Foundation; Conselho de Avaliação e Regulação de Educação Superior de Taiwan (HEEACT, 2008) (pesquisa); Sistemas de cálculo de publicaçóes e citaçóes - Thomson-ISI and Elsevier-Scopus (2007) (Morosini; Sousa, 2008).

É importante registrar que a perspectiva da qualidade isomórfica ainda é bastante forte, mas nem tanto. O braço da EAIR, nos Estados Unidos, é a American Association on Institutional Research (AAIR), voltada à melhoria das IES e ao desen-

que proporcionou informações sobre "La Educación Superior y el Empleo de Graduados Universitarios en Europa". A coordenação esteve sobre a égide de três universidades europeias: a Universidade de Kassel, Alemanha (coordenadora do projeto CHEERS); a Universidade de Maastricht, Países Baixos (coordenadora do projeto REFLEX) e a Universidade Politécnica de Valencia, Espanha. Atualmente, a Universidade de Valencia está coordenando o projeto PROFLEX (El Profesional Flexible en la Sociedad del Conocimiento), com os mesmos objetivos, mas tendo como empiria a América Latina (CEGES, 2008). 
volvimento de estratégias de avaliação para fundamentar o planejamento institucional ${ }^{16}$. O tema do encontro de 2008 foi: "Adaptando-se ao enfrentamento de novos desafios", focados na perspectiva abaixo:

Institutional Research has moved beyond mainly counting students and faculty to influencing assessment, planning, forecasting, tracking and a multitude of other activities; and, of course, we still count students and faculty. One of the greatest attributes for an institutional researcher is the ability to adapt; whether it be developing a new set of skills, responding to institutional needs, or changing directions in the middle of a study, being able to adapt is required of all institutional researchers. As the population changes, budgets change and calls for accountability increase, the institutional researcher will be in front, providing the information needed to meet these challenges. ${ }^{17}$ (AAIR, 2008)

\section{CONCLUSÕES PROVISÓRIAS}

Em razão das consideraçóes realizadas neste texto, algumas conclusões podem ser apresentadas.

A concepção de qualidade sofre pressão e direcionamento dos organismos multilaterais. A exigência da qualidade da educação, com os tipos de isomorfismo, diversidade e equidade, se mantém no início deste século. Entretanto, ocorre a minimização entre as fronteiras da tipologia proposta em 2001 e a acima referida. Sem

\footnotetext{
${ }^{16}$ Podemos citar, como exemplos, alguns minicursos ofertados no seminário de Seatle: S.O.S.: Soluçôes de resultados estudantis para programas de avaliação; Regressão Logística - interpretação e aplicação na educação superior para admissão, permanência, e avaliação de resultados; Análise de sobrevivência; Construçấo de tabela de pontos de balanço institucional - identificação de medidas, benchmarks e displays para atender as necessidades dos usuários; Principais modelos de prediçáo; Caminhos para a efetividade institucional: alinhando o processo de planejamento e o programa de avaliação institucional; Revendo diferentes estratégias para avaliar os resultados gerais da educação: examinando as conexôes entre pensamento crítico, escrita e comunicação oral, etc.

${ }^{17}$ A pesquisa institucional ultrapassou as simples estatísticas, principalmente de estudantes e faculdades, para influenciar a avaliação, o planejamento, a previsão, o monitoramento e uma infinidade de outras atividades, e, naturalmente, ainda realiza o censo dos estudantes e faculdades. Um dos maiores atributos de um pesquisador institucional é a capacidade de adaptação, quer desenvolvendo um novo conjunto de competências, que respondam às necessidades institucionais, quer mudando o direcionamento no meio de um estudo. À medida que a população muda, que orçamentos são alterados e há pressōes para o aumento da prestação de contas, o pesquisador institucional estará à frente, fornecendo as informaçóes necessárias para responder a esses desafios.
} 
dúvida, o contexto sócio-histórico tem interferido nessa caminhada conceitual. Não podemos esquecer que na Uniáo Europeia foram anexados mais 27 países com realidades diversas dos tradicionais integrantes desenvolvidos, como, por exemplo, os países da Escandinávia. Logo, a busca da qualidade, ainda com o predomínio do tipo isomórfico, está ligada à diversidade e à consideração da equidade. Paralelamente, a certeza da qualidade isomórfica/universal passa a ser questionada e a qualidade institucional/diversidade passa a ser defendida. Haja vista os temas das associaçóes referentes à educação superior, como a European Association on Institutional Research $(E A I R)$, que comandam as pesquisas e as orientaçóes para administradores e pesquisadores da educação superior na Europa.

Nesta trajetória a Unesco desempenha papel fundamental. Ela envolve 96 países e tem ramificaçóes nos diversos continentes. A sua força está ligada ao espraiar de suas associaçóes. É aí que o tema da qualidade e de suas características vem se concretizando, na consideração da realidade dos diferentes continentes.

Diante do quadro acima, extremamente resumido, a concepção de responsabilidade social universitária, hoje, se destaca. É importante registrar alguns aportes de substituição/minimização do conceito de Responsabilidade Social Universitária pelo de Oportunidade Social Universitária, que envolve a consideração não só dos deveres como também dos direitos da instituição.

Paralelamente, a qualidade isomórfica ainda é predominante nos USA e na Austrália, ainda que atenuada em suas determinaçóes. A postura isomórfica, provavelmente, é influenciada pela maior similaridade entre a população da educação superior nos USA e a necessidade de avaliação, em um sistema onde a competição, o mercado e a individualidade dominam. As associaçóes, neste caso, a American Association on Institutional Research (AAIR), se destaca na orientação às IES e vem desenvolvendo medidas de desempenho para atender a este mercado. Inúmeros são os produtos colocados à venda para auxiliar as instituiçóes a se avaliarem, a atraírem, reterem e inserirem, no mercado, seus alunos, bem como a terem impacto na sociedade. Mas nesse contexto algumas verdades também estão sendo questionadas. A presença de populaçóes latinas e outras, oriundas de etnias não brancas, levam à necessidade de ampliação do acesso à educação superior com qualidade e de incentivo à permanência. Segundo Pareto (1987), tais determinantes, se não atendidos, podem pôr em risco não só a hegemonia da elite, com o perigo das tensóes internas desmantelarem a unidade monolítica, mas também a brain gain - conquista de cérebros, podendo ser substituída pela brain drain perda de cérebros. 
Tanto em 2001, quando escrevi o primeiro texto, como hoje, a concepção de qualidade não é clara. Da mesma forma, também cabe esclarecer a quem ela é dirigida e por quem ela é definida. E aqui fica fortalecida a tendência de colocar o foco no estudante, e mais recentemente no egresso - learning outcomes.

A certeza que temos é que qualidade é um construto imbricado no contexto das sociedades e consequentemente nos paradigmas de interpretação da sociedade e do papel da educação superior na construçáo de um mundo melhor e, me atreveria a dizer, sustentável. Cumpre também pensarmos e implantarmos efetivamente a concepção de qualidade como equidade.

\section{REFERÊNCIAS BIBLIOGRÁFICAS}

AMERICAN ASSOCIATION ON INSTITUTIONAL RESEARCH. Presentation. Disponível em: $<$ http://www.airweb.org/?page $=1134>$. Acesso em: 28 jun. 2008.

ASSOCIATION INTERNATIONALE DE PEDAGOGIE UNIVERSITAIRE. Presentation. Disponível em: <http://www.aipu2008montpellier.fr/index.php?dossier_ nav $=637 \# T 1>$. Acesso em: 24 abr. 2008.

CEGES. PROFLEX: el profesional flexible en la sociedad del conocimiento. Disponível em: $<$ http://www.ceges.upv.es $>$. Acesso em: 23 maio 2008.

CONFERÊNCIA

INTERNACIONAL

$\mathrm{DE}$ BARCELONA SOBRE EDUCAÇÃO SUPERIOR, 4. 2008, Barcelona. Anais eletrônicos... Disponível em: $\quad<$ http://www.guni-rmies.net/k2008>. Acesso em: 6 dez. 2007.

DELORS, J. et al. Educação: um tesouro a descobrir. São Paulo: Cortez, 2006.

ENCONTRO INTERNACIONAL DE REITORES EM TORNO AO TEMA DO COMPROMISSO SOCIAL, 2007, Minas Gerais. Anais... Disponível em: <http://www.iesalc.org>. Acesso em: 11 nov. 2007.

EUROPEAN ASSOCIATION ON INSTITUTIONAL RESEARCH. Thacks. Disponível em: <http:// www.eair.nl/Insbruch/theme/>. Acesso em: 13 jul. 2006.

. Theme. Disponível em: <http:// www.eair.nl/copenhagen/theme/>. Acesso em: 28 jun. 2008.

FELICETTI, V.; MOROSINI, M. C. Equidade e iniquidade no ensino superior: uma reflexão. Ensaio. Rio de Janeiro, 2009. No prelo.

HARVEY, Lee. New realities: the relationship between higher education and employment. European Association of Institutional Research. Lund: August, 1999. Disponível em: <http:// www.uce.ac.crq/publications/cp/eair99>. Acesso em: 15 set. 2000.

INSTITUT NATIONAL DE CALIDAD Y EVALUACION. Equidad y calidad en educación. Revista de Educación, Madrid, n. 319, mayo/ago. 1999.

KNIGHT, Peter; YORKE, Mantz. Assesment, learning and employability. London: The Society for Research into Higher Education; Open University Press, 2003.

LA JARA, Mónica Jiménez de. Universidad Construye País. Disponível em <http:// www.guni-rmies.net/k2008/page. php?lang=2\&id=32>. Acesso em: $6 \mathrm{dez}$. 2007.

MARGINSON,S.AFunnything happened on the way to the k-economy the new world order in highereducation:researchrankings, outcomes measures and institutional classifications. In: GENERAL CONFERENCE IMHE. PROGRAMME ON INSTITUTIONAL MANAGEMENT IN HIGHER EDUCATION. CONFERENCE PAPERS, Paris. Anais... Disponível em: <http://www.oecd. 
org/dataoecd/60/25/41203671.pdf>. Acesso em: 23 set. 2008.

MOROSINI, M. C. Qualidade universitária: isomorfismo, diversidade e equidade. Interface: comunicação, saúde e educação, v. 5, n. 9, p. 89-102, 2001.

- O Professor do ensino superior na sociedade contemporânea. In: ENRICONE, D. Sete olhares sobre a educação superior. Porto Alegre: Ed PUCRS, 2006.

MOROSINI, M. C.; SOUSA, A. Limites e desafios do sistema nacional de avaliação da educação superior. Bahia: Ed UFFS, 2008. No prelo.

NOORDA, Sijbolt. Presentation. In: GENERAL CONFERENCE IMHE. PROGRAMME ON INSTITUTIONAL MANAGEMENT IN HIGHER EDUCATION. CONFERENCE PAPERS, Paris. Anais... Disponível em: <http://www.oecd. org/document/8/0,3343,en_21571361_ 38973579_41027656_1_1_1_1,00.html >. Acesso em: 28 set. 2008.

PARETO, V. Manual de Economia Política. 2. ed. São Paulo: Nova Cultural, 1987.

SANTIAGO, P. et al. OECD thematic review of tertiary education: synthesis report. Synthesis report of the tertiary education for the knowledge society. In: INTERNATIONAL CONFERENCE TO PRESENT THE RESULTS OF THE OECD THEMATIC REVIEW OF TERTIARY EDUCATION. 2008, Lisboa. Anais... Disponível em: <http://www.oecd.org/ dataoecd/59/37/40330439.pdf >. Acesso em: 15 maio 2008.

SCHOMBURG, H.; TEICHLER, U. Employment outcomes of young graduates in Europe and Japan - empirical evidence from CHEERS and REFLEX. In: GENERAL CONFERENCE. IMHE. PROGRAMME ON INSTITUTIONAL MANEGEMENT IN HIGHER EDUCATION. CONFERENCE PAPERS. 2008, Paris. Anais... Disponível em: <http://www.oecd.org/ dataoecd/13/2/41344325.pdf>. Acesso em: 15 maio 2008.

UNESCOPRESSE n. 2001-35. Los países de América Latina y el Caribe adoptan la declaración de Cochabamba sobre educación. In: OFICINA DE INFORMACIÓN PÚBLICA PARA AMÉRICA LATINA Y EL CARIBE. 2001. Anais... Disponível em: <http://www.iesalc.org>. Acesso em: 13 mar. 2001.

UNESCO. Mesa redonda ministerial sobre "educación y desarrollo económico". In: REUNIÓN DE LA CONFERENCIA GENERAL DE LA UNESCO, 34으. 2007, Paris. Comunicado... Disponível em: <http://portal.unesco.org/ education/es/ev.phpurl_id=27542\&url_ do=do_topic\&url_section=201.html>. Acesso em: 6 dez. 2007.

VALLAEYS, F. Responsabilidad social. In: REUNIÓN DE AUSJAL, 2007, Caracas. Anais... Disponível em: <http://www.guni-rmies.net/ k2008/page.php?lang=2\&id=32>. Acesso em: 6 dez. 2007.

ZAFFARONI, Cecilia. Universidad con responsabilidad sustentable. In: REUNIÓN AUSJAL, 2007, Caracas. Anais... Disponível em: <http://www.guni-rmies.net/k2008/page. php?lang=2\&id=32>. Acesso em: 6 dez. 2007.

Recebido em: janeiro 2009

Aprovado para publicação em: abril 2009 


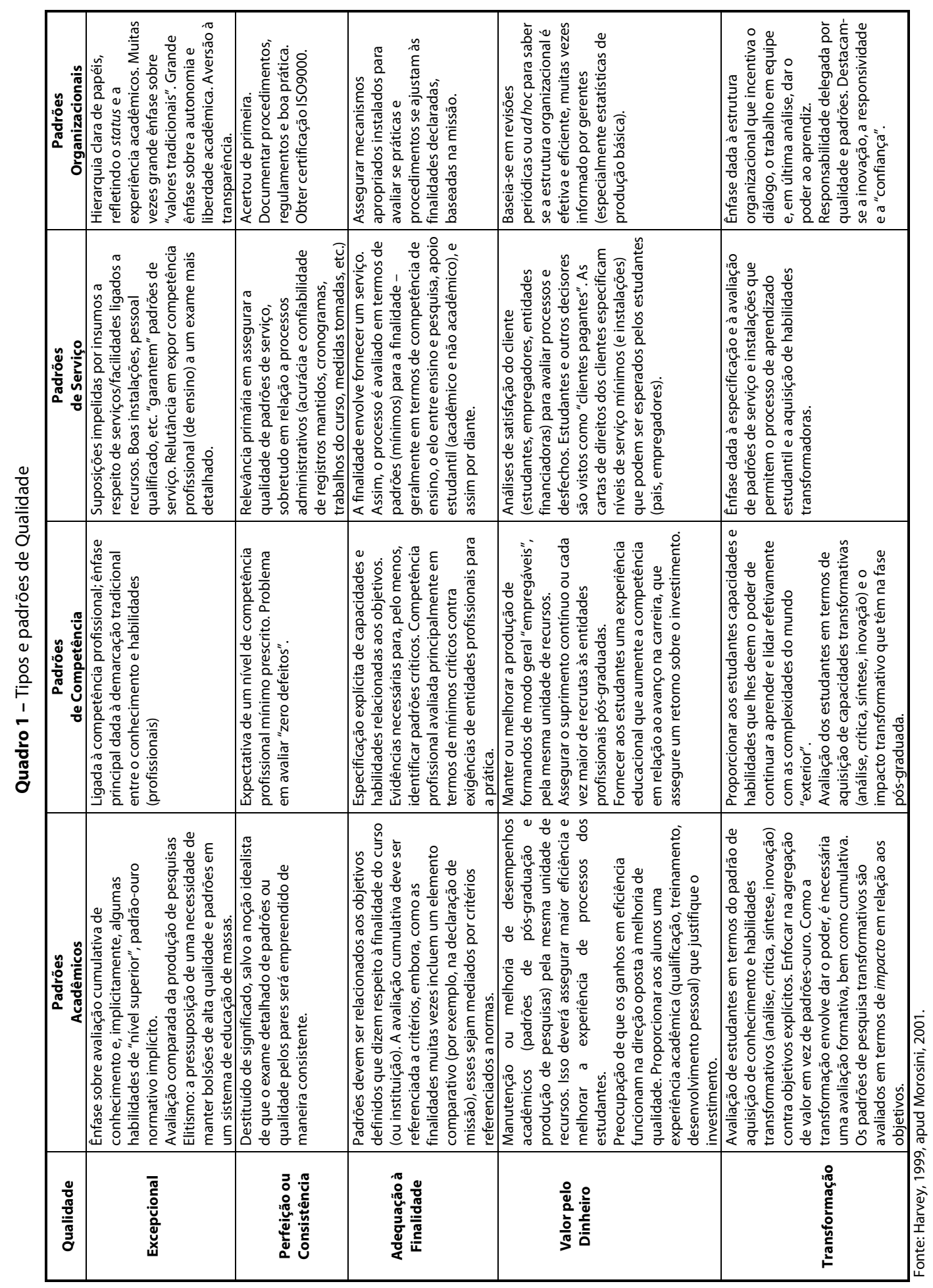

186 • Est. Aval. Educ., São Paulo, v. 20, n. 43, maio/ago. 2009 